\title{
The electronic properties of transition metal hydrogen complexes in silicon
}

\author{
R. Jones $^{\mathrm{a}, 1}$, A. Resende ${ }^{\mathrm{a}}$, S. Öberg ${ }^{\mathrm{b}, 2}$ and P. R. Briddon ${ }^{\mathrm{c}}$ \\ ${ }^{a}$ Department of Physics, The University of Exeter, Exeter, EX4 4QL, \\ United Kingdom \\ b Department of Mathematics, University of Luleå, Luleå, S95 187, Sweden \\ ${ }^{\mathrm{c}}$ Department of Physics, The University of Newcastle upon Tyne, \\ Newcastle upon Tyne, NE1 7RU, United Kingdom
}

\begin{abstract}
The electrical levels of various combinations of transition metal- $\mathrm{H}_{n}$ defects in Si are calculated using spin-polarised local density functional cluster theory with an empirical correction. The shifts of these levels with $\mathrm{H}$ can be understood through a displacement and splitting of the gap $t_{2}$ manifold of states due to the impurity. Passive defects are identified.
\end{abstract}

Key words: transition-metal impurities, $\mathrm{H}, \mathrm{Si}$, complexes, ab initio theory.

\section{Introduction}

The transition metals $\mathrm{Au}, \mathrm{Ag}, \mathrm{Pt}$ and $\mathrm{Pd}$ form substitutional defects in $\mathrm{Si}$ with a simple energy level structure. They possess donor or $(0 /+)$ levels around $E_{v}+0.35$ $\mathrm{eV}$ and, in the case of $\mathrm{Au}$ and $\mathrm{Ag}$, acceptor or $(-/ 0)$ levels at $\sim E_{c}-0.55 \mathrm{eV}$. Pt and $\mathrm{Pd}$ have $(-/ 0)$ levels around $E_{c}-.23 \mathrm{eV}$ and double donor $(+/++)$ levels around $E_{v}+.1 \mathrm{eV}$.

From a theoretical viewpoint, the energy levels are understood to rise from the $t_{2}$ manifold lying deep in the gap and occupied by 3 electrons for neutral $\mathrm{Au}$ and $\mathrm{Ag}$ and 2 for Pt and Pd. Most calculations do not give the correct Si band gap and there

$\overline{1 \text { EPSRC }}$ and the ENDEASD network are thanked for computer time and financial support respectively.

2 Financially support by NFR and TFR, and computer support by PDC at KTH in Sweden are gratefully acknowledged. 
is then a problem in calculating these levels. We show here that using a combination of first principles theory and an empirical correction to the level position, the donor and acceptor levels can be found to within about $0.2 \mathrm{eV}$. The method we use is described below and applied to a number of deep level defects as well as to Ag, $\mathrm{Au}$, $\mathrm{Pd}$ and $\mathrm{Pt}$ impurities. We also investigate the effect of bringing $\mathrm{H}$ atoms up to the impurity and compare these with experimental results using capacitance transient spectroscopic techniques on Si doped with $\mathrm{Ag}, \mathrm{Au}, \mathrm{Pd}$ and $\mathrm{Pt}$ into which hydrogen has been introduced.

A density functional cluster scheme, applied to large H-terminated clusters, is used to first deduce the structure of the defect [1], but an extension to this procedure must be sought if the electrical levels are required. The $(0 /+)$ level with respect to $E_{v}$ is the difference between the ionisation energy of the defect and that of bulk Si. If the wavefunction of the defect is localised within the cluster, then in principle the ionisation energy of the defect can be calculated by the cluster method. However, as the valence band wavefunctions are always extended throughout the cluster and affected by the surface, the bulk ionisation energy cannot be calculated by the method. To circumvent this problem we compare the ionisation energy of the defect, $I_{d}$, with that of a standard defect, $I_{s}$ (taken to be $\mathrm{C}_{i}$ ), with localised levels. The $(0 /+)$ level is then the sum of $I_{s}-I_{d}$ and the $(0 /+)$ level of $\mathrm{C}_{i}$, i.e. $0.28 \mathrm{eV}$. In the same way the electron affinities can be used to determine the acceptor level relative to that of $\mathrm{C}_{i}$.

By comparing the ionisation energies of defects in this way, we can eliminate a systematic shift in the calculated levels caused by the cluster surface. This follows as the wavefunction for the ionised defect will decay exponentially away from the centre of the cluster, and the shift in the level position caused by the surface, to first order, then depends only on the asymptotic part of the wavefunction. Clearly, this decay is related to the depth of the level from the band edges and the shift would be the same for the standard defect if the latter possessed the same energy level and the same total charge within the core. In the same way, the error in estimating the Hubbard $U$-parameter would be the same as in the standard defect if $U$ depended only on the asymptotic part of the wavefunction. Thus we expect that the error in estimates of the levels to increase with the separation between the defect level and that of the standard. In practice, the ionisation energies and electron affinities are calculated from the Kohn-Sham levels by relaxing the transition state corresponding to an additional $1 / 2$ electron or hole. In this way the effect of a change in structure between the ionised and neutral defects is treated to first order. This technique supersedes an earlier one based on scaling the band gap although the two methods give rather similar results [2].

The clusters used either contained 131 atoms $\left(\mathrm{Si}_{71} \mathrm{H}_{60}\right)$ with $T_{d}$ symmetry centred on an atom, or $134\left(\mathrm{Si}_{68} \mathrm{H}_{66}\right)$ atoms with $D_{3 d}$ symmetry and centred on the middle of a bond. The latter was used for 'trigonal' defects like $\mathrm{H}_{\mathrm{BC}}, \mathrm{V}_{2}$ etc. Usually, the clusters were relaxed with the $\mathrm{H}$ atoms fixed. However, for vacancy-like defects, eg 
$\mathrm{VP}, \mathrm{V}_{2}$ and $\mathrm{VO}$, the clusters were prerelaxed to force a strong reconstruction across the Si dangling bonds and all atoms were then relaxed. Second acceptor levels of defects can also be found by comparing the second electron affinities with that of $\mathrm{PtH}_{2}$. The (- - / ) level of this defect is believed to lie between $0.045 \mathrm{eV}$ and 0.1 $\mathrm{eV}$ below $E_{c}$ and we assume a value of $0.07 \mathrm{eV}$.

\section{Results}

Calculations were carried out for the standard defect $\mathrm{C}_{i}$, and $\mathrm{C}_{i}$-P, the T-centre $\left(\mathrm{C}_{s^{-}}\right.$ $\left.\mathrm{C}_{i} \mathrm{H}\right), \mathrm{H}$ at a bond centred site $\left(\mathrm{H}_{\mathrm{BC}}\right), \mathrm{H}$ at anti-bonded lattice site, $\mathrm{H}_{\mathrm{AB}}, \mathrm{VO}, \mathrm{VP}$, $\mathrm{V}_{2}, \mathrm{Au}, \mathrm{Ag}, \mathrm{Pt}, \mathrm{Pd}, \mathrm{AuH}_{n}, \mathrm{AgH}_{n}, \mathrm{PdH}_{n}$ and $\mathrm{PtH}_{n}$ and the results are given in Table 1 where they are compared with experimental values.

In general the calculated electrical levels of light impurities are within about $0.2 \mathrm{eV}$ of the experimental results where available. Whereas the donor and acceptor levels of $\mathrm{C}_{s}-\mathrm{C}_{i} \mathrm{H}, \mathrm{C}_{i} \mathrm{P}, \mathrm{VP}, \mathrm{VO}$ and even $\mathrm{V}_{2}$ are within $0.2 \mathrm{eV}$ of the experimental values, it is surprising that the $0 /+$ level of $\mathrm{H}_{\mathrm{BC}}$ is found so close to the observed level given that the theory is expected to be worse when the level moves far away from that of $\mathrm{C}_{i}$. For $\mathrm{Ag}, \mathrm{Au}, \mathrm{Pd}$ and $\mathrm{Pt}$, all in low spin configurations, we find the $(-/ 0)$ and $(0 /+)$ levels to be deep in the gap and within $0.2 \mathrm{eV}$ of the observed values. We now investigate the effect of adding $\mathrm{H}$ atoms to these defects.

\subsection{Au and Ag hydrogen defects}

There are two likely sites for $\mathrm{H}$ next to the TM impurity. Either $\mathrm{H}$ lies inside the vacancy or outside with approximate trigonal symmetry. The energy difference between these structures is a sensitive function of basis size and previously [2] we reported preliminary results using a modest sized basis. We have now repeated these with a much larger basis described above and find, in contrast with the previous results, that the most stable structures are generally with the $\mathrm{H}$ atoms outside the vacancy. However, the energy differences are not large. For example, in the case of $\mathrm{Au}-\mathrm{H}$, the energy of $\mathrm{H}$ anti-bonded to a Si neighbour ( $\mathrm{AB}$ site) is lower by $0.23 \mathrm{eV}$ than when $\mathrm{H}$ lies inside the vacancy at an AB site. Structural details are reported in [7]. Here we concentrate on the electrical activity of the various defects.

The electrical levels are determined by the shift and splitting of the $t_{2}$ manifold. In each case we assumed that a low spin state results from the addition of H. Since the wavefunction of the added electron is distributed over several shells of atoms, it is unable to completely screen the additional proton. This results in a downward shift of the $t_{2}$ manifold and opens the possibility for a second acceptor level. However, the $t_{2}$ manifold is split by the presence of $\mathrm{H}$ and this can result in an upward 


\begin{tabular}{|c|c|c|c|c|c|}
\hline Defect & $E(0 /+)$ Calc. & $E(0 /+)$ Observed & $E(-/ 0)$ Calc. & $E(-/ 0)$ Observed & Ref. \\
\hline VP & 0.2 & - & 0.45 & 0.43 & \\
\hline VO & 0.0 & - & 0.13 & 0.18 & \\
\hline $\mathrm{V}_{2}\left(C_{2 h}\right)$ & 0.42 & 0.23 & 0.51 & 0.43 & \\
\hline $\mathrm{C}-\mathrm{CH}$ & 0.24 & $?$ & 0.20 & 0.20 & \\
\hline $\mathrm{C}_{i} \mathrm{P}$ & 0.36 & 0.48 & 0.60 & 0.38 & \\
\hline $\mathrm{H}_{\mathrm{BC}}$ & 0.94 & 1.0 & - & - & \\
\hline $\mathrm{H}_{\mathrm{AB}}$ & - & - & 0.78 & $?$ & \\
\hline $\mathrm{V}_{2} \mathrm{O}$ & - & - & 0.47 & - & \\
\hline $\mathrm{Ag}$ & 0.46 & 0.37 & 0.60 & 0.56 & ref. [3] \\
\hline $\mathrm{AgH}$ & 0.36 & $0.28(\mathrm{H} 2) ?$ & 0.45 & 0.45 (E2)? & ref. [3] \\
\hline $\mathrm{AgH}_{2}$ & 0.33 & $0.38(\mathrm{H} 3) ?$ & 0.50 & - & ref. [3] \\
\hline $\mathrm{AgH}_{3}$ & 0.0 & - & 0.13 & - & \\
\hline $\mathrm{AgH}_{4}$ & 0.0 & - & 0.97 & - & \\
\hline $\mathrm{Au}$ & 0.21 & 0.35 & 0.66 & 0.54 & ref. [4] \\
\hline $\mathrm{AuH}$ & 0.36 & $0.21(\mathrm{G} 2) ?$ & 0.62 & $\sim 0.53(\mathrm{G} 4) ?$ & ref. [4] \\
\hline $\mathrm{AuH}_{2}$ & 0.28 & $0.47(\mathrm{G} 3) ?$ & 0.62 & - & ref. [4] \\
\hline $\mathrm{AuH}_{3}$ & 0.0 & - & 0.26 & - & \\
\hline $\mathrm{AuH}_{4}$ & - & - & 1.4 & - & \\
\hline $\mathrm{Pd}$ & 0.52 & 0.31 & 0.22 & 0.23 & ref. [5] \\
\hline $\mathrm{PdH}$ & 0.53 & $0.55(\mathrm{H} 280) ?$ & 0.39 & 0.29 (E160)? & ref. [5] \\
\hline $\mathrm{PdH}_{2}$ & 0.0 & - & 0.39 & 0.43 (E200)? & ref. [5] \\
\hline $\mathrm{PdH}_{3}$ & 0.0 & - & 1.0 & $1.0(\mathrm{H} 140) ?$ & ref. [5] \\
\hline $\mathrm{PdH}_{4}$ & - & - & 0.53 & - & \\
\hline $\mathrm{Pt}$ & 0.23 & 0.35 & 0.36 & 0.23 & ref. [6] \\
\hline $\mathrm{PtH}$ & 0.52 & $0.4(\mathrm{H} 210) ?$ & 0.42 & - & ref. [6] \\
\hline $\mathrm{PtH}_{2}$ & 0.0 & - & 0.45 & $0.50(\mathrm{E} 250) ?$ & \\
\hline $\mathrm{PtH}_{3}$ & 0.0 & $?$ & 1.4 & 0.9 (H150) & ref. [6] \\
\hline $\mathrm{PtH}_{4}$ & - & - & 1.0 & - & \\
\hline
\end{tabular}

Table 1

Electrical levels, eV, of deep centres. $(0 /+)$ is referred to $E_{v}$ and $(-/ 0)$ to $E_{c}$. Tentative assignments are indicated by ?. 
Table 2

\begin{tabular}{|l|c|c|r|}
\hline Defect & $E(--/-)$ Calc. & $E(--/-)$ Obs. & Ref. \\
\hline $\mathrm{V}_{2}$ & 0.35 & $0.23 ?$ & \\
$\mathrm{AgH}$ & 0.36 & 0.09 (E3)? & ref. [3] \\
$\mathrm{AuH}$ & 0.22 & $0.19(\mathrm{G} 1) ?$ & ref. [8] \\
$\mathrm{AgH}_{2}$ & 0.0 & - & \\
$\mathrm{AuH}_{2}$ & 0.0 & - & \\
$\mathrm{PdH}$ & $\sim 0.0$ & - & \\
$\mathrm{PdH}_{2}$ & $\sim 0.0$ & - & \\
$\mathrm{PtH}$ & 0.12 & - & \\
$\mathrm{PtH}_{3}$ & 0.0 & - & \\
\hline
\end{tabular}

$(--/-)$ levels of deep centres, relative to $E_{c}$, in $\mathrm{eV}$. Tentative assignments are indicated by ?.

movement of the higher levels.

In the case of $\mathrm{Ag}$, the addition of one $\mathrm{H}$ atom, with approximate trigonal symmetry, leads to downward shift in the donor level and an upward shift in the acceptor level. This is because the $t_{2}$ level is split into an $a_{1}$ (filled) level lying below a half-filled $e$ level. The lowering of the $t_{2}$ manifold is then compensated by the splitting. A second $\mathrm{H}$ atom results in an additional electron occupying the $e$ level and the shift in the level is dominated by a downward shift in the manifold although this is reduced by an upward shift caused by a symmetry induced splitting of the $e$ level. Adding a third $\mathrm{H}$ fills the $e$ level and the $t_{2}$ manifold is pushed below the valence band top. Thus $\mathrm{AgH}_{3}$ and $\mathrm{AuH}_{3}$ do not possess any donor levels. However, it appears that an empty level, due, we believe to the $5 s$ and $6 s$ levels of $\mathrm{Ag}$ and $\mathrm{Au}$, creeps into the band gap. We place the resulting $(-/ 0)$ levels of $\mathrm{AgH}_{3}$ and $\mathrm{AuH}_{3}$ at 0.13 and 0.26 $\mathrm{eV}$ below $E_{c}$. It may be that these levels are in reality much more shallow and thus substitutional $\mathrm{Ag}$ and $\mathrm{Au}$ can be passivated by three $\mathrm{H}$ atoms.

Experimentally, the levels for $\mathrm{Ag}[3]$ and $\mathrm{Au}[4,8]$ hydrogen defects are rather similar. For the former impurity, the $\mathrm{H} 2$ level at $0.28 \mathrm{eV}(0 /+)$ and $\mathrm{E} 2$ at $0.45 \mathrm{eV}$ $(-/ 0)$ have been assigned to $\mathrm{Ag}-\mathrm{H}$, while the $\mathrm{G} 2$ level at $0.21 \mathrm{eV}$ and $\mathrm{G} 4$ at $~$ $0.53 \mathrm{eV}$ have been assigned to the $(0 /+)$ and $(-/ 0)$ levels of $\mathrm{Au}-\mathrm{H}$. Although the calculated values for $\mathrm{AgH}$ and $\mathrm{AuH}$ are in fair agreement with these assignments, we cannot rule out an assignment to $\mathrm{AgH}_{2}$ and $\mathrm{AuH}_{2}$. However, the calculated $(--/-)$ levels for $\mathrm{AgH}$ and $\mathrm{AuH}$ are reasonably close to $\mathrm{E} 3(0.09 \mathrm{eV})$ and $\mathrm{G} 1$ $(0.19 \mathrm{eV})$ respectively, while $\mathrm{AgH}_{2}$ and $\mathrm{AuH}_{2}$ do not appear to possess (- - / ) levels. This is probably the result of the filling of the $t_{2}$ manifold. We thus conclude that the observed levels are due to a single $\mathrm{H}$ atom complexed with the impurity.

The $\mathrm{H} 3$ level at $0.38 \mathrm{eV}$ has been assigned to the $(0 /+)$ level of $\mathrm{AgH}_{2}$ while the $\mathrm{G} 3$ 
level at $0.47 \mathrm{eV}$ to a $\mathrm{Au}-\mathrm{H}_{2}$ defect. Although this is consistent with our calculations, there are no reports of associated $(-/ 0)$ levels. We place these close to E2 and G4. The absence of these levels places doubts on the assignments.

Both defects $\mathrm{Ag}$ and $\mathrm{Au}$ can be passivated and our calculations suggest that $\mathrm{AgH}_{3}$ and $\mathrm{AuH}_{3}$ are candidates given our errors can be around $0.2 \mathrm{eV}$. However, we describe below a different defect which is electrically inactive. $\mathrm{AuH}_{4}$ and $\mathrm{AgH}_{4}$ defects possess deep acceptor levels reminiscent of $\mathrm{H}_{\mathrm{AB}}$.

\subsection{Pt and Pd hydrogen defects}

$\mathrm{PtH}$ and $\mathrm{PdH}$ have donor and acceptor levels lying deeper in the gap than those of $\mathrm{Pt}$ and $\mathrm{Pd}$ respectively. Adding a second $\mathrm{H}$ atom, however, results in a rapid drop in the $t_{2}$ manifold and the donor levels are pushed into the valence band. The acceptor levels are, however, hardly affected. The (- - / ) level of $\mathrm{PdH}_{2}$ appears to be very shallow. $\mathrm{PtH}_{3}$ and $\mathrm{PdH}_{3}$ defects are particularly interesting as the donor levels are absent and the acceptor levels are very deep. It seems that there is strong affinity to fill the $t_{2}$ manifold. These $(-/ 0)$ levels are calculated to lie $1.4 \mathrm{eV}$ and $1.0 \mathrm{eV}$ below $E_{c}$ although of course the error in the estimates increases with the depth. $\mathrm{PtH}_{4}$ and $\mathrm{PdH}_{4}$ also possess deep acceptor levels probably related to the $5 s$ and $6 s$ levels being brought into the gap.

Experimentally, in Pt doped hydrogenated $p$-Si, a level at $E_{v}+.4 \mathrm{eV}(\mathrm{H} 210)$ is formed below $400 \mathrm{~K}$, which upon annealing is converted into a deep acceptor, at $E_{c}-.9 \mathrm{eV}$ (H150) [6]. This defect dissociates into Pt above 530K. In $n$-Si, two levels at $E_{c}-.18 \mathrm{eV}(\mathrm{E} 90)$ and $E_{c}-.5 \mathrm{eV}(\mathrm{E} 250)$ are formed around $300 \mathrm{~K}$ but these dissociate above $600 \mathrm{~K}$. At lower annealing temperatures around $300 \mathrm{~K}$, they convert into $\mathrm{H}(150)$. However, $\mathrm{H}(150)$ converts into $\mathrm{H}(210)$ in $p$-Si and $\mathrm{E}(250)$ in $n$-Si above about $500 \mathrm{~K}$. The emission rate of $\mathrm{E}(90)$ increases with electrical field suggesting it is a donor. The $\mathrm{H}(150)$ acceptor is formed where the $\mathrm{H}$ concentration is maximum and a rough estimate is that this centre contains 2 to 3 times as much $\mathrm{H}$ as $\mathrm{E}(90)$ and $\mathrm{E}(250)$. The latter anneal out at slightly different temperature indicating that they are distinct defects -as are $\mathrm{E}(250)$ and $\mathrm{H}(210)$.

The results in Table 1 suggest that the deep acceptor, $\mathrm{H}(150)$, is likely to be $\mathrm{PtH}_{3}$ or $\mathrm{PtH}_{4}$. There are no associated donor levels. Only $\mathrm{PtH}$ has a deep donor and we assign this to $\mathrm{H}(210)$. This suggests that $\mathrm{E}(250)$ is the $(-/ 0)$ level of $\mathrm{PtH}_{2}$ as this defect is believed to be distinct from $\mathrm{H}(210)$. This leaves the $(-/ 0)$ level of $\mathrm{PtH}$ to be detected. The calculations give no support to the idea that the donor level around $E_{c}-.18 \mathrm{eV}$ (E90) is a Pt-hydrogen defect. Nor could this level be the $(--/-)$ level in this region detected in EPR [9]. However, its character and location suggests a $(0 /+)$ level associated with bond centred $\mathrm{H}$ trapped near an unknown neutral $\mathrm{Pt}$ related complex. 
EPR experiments [9] demonstrate that the $\mathrm{PtH}_{2}$ defect has a (-/0) level between 0.23 and $0.87 \mathrm{eV}$ below $E_{c}$. We place it at $E_{c}-.45 \mathrm{eV}$ and identify it with $\mathrm{E}(250)$. However, disturbingly there are no DLTS levels reported for the $(--/-)$ level of $\mathrm{PtH}_{2}$.

More levels have been detected for $\mathrm{Pd}-\mathrm{H}_{n}$ defects [5]. A suggested correspondence between the Pt and Pd levels allows us to tentatively assign the $\mathrm{H}(280)$ and $\mathrm{E}(200)$ levels to $\mathrm{PdH}$ and $\mathrm{PdH}_{2}$ respectively, and $\mathrm{H}(140)$ to the deep acceptor level of $\mathrm{PdH}_{3}$. The presence of an additional DLTS level, namely E(160) at $E_{c}-.29 \mathrm{eV}$, which is close to the calculated $(-/ 0)$ level of $\mathrm{PdH}$ suggests that this is the acceptor level missing in PtH. Thus the two levels $\mathrm{E}(160)$ and $\mathrm{H}(280)$ should be correlated. Two hole traps $\mathrm{H}(45)$ and $\mathrm{H}(55)$ around $0.08 \mathrm{eV}$ may be due to double donor levels of $\mathrm{PdH}$ where the $\mathrm{H}$ is separated by different distances from Pd. Similarly, if $\mathrm{E}(60)$ is a donor level analogous with the Pt related E(90) level, then it must be related to $\mathrm{H}_{\mathrm{BC}}$ close to a neutral defect. Apparently Pd can be passivated in contrast with what has been reported for Pt. The calculations do not show that substitutional Pd or Pt can be passivated but we now describe a defect which is inactive.

\subsection{Void and Multivacancy Defects}

Transition metal impurities have a large atomic radius and are readily attracted to voids or multivacancies. Indeed, there have been several studies of the gettering effect of voids [10]. Within the void, there is a possibility of a molecular hydride species being formed as for example, $\mathrm{AuH}, \mathrm{AgH}, \mathrm{PtH}_{2}$ and $\mathrm{PdH}_{2}$. The molecular species are known to be thermally stable, e.g. AuH has a dissociation energy of $3.1 \mathrm{eV}$. To investigate their properties within $\mathrm{Si}$, calculations were carried out on clusters containing a decavacancy whose surface is saturated with $\mathrm{H}$. The ionisation energies and electron affinities of TMH hydrides inserted into this microvoid demonstrated that these defects possess no gap levels and as such represent a means by which the impurity is passivated. However, whereas it is known that voids form in plasma treated or $\mathrm{H}$-implanted material, it is unclear whether they, or multivacancy centres, can be produced by wet etching.

\section{Conclusions}

The calculations of the electrical levels of the TM-H defects have allowed us to assign several observed levels to defects containing up to $3 \mathrm{H}$ atoms. Whereas $\mathrm{AuH}_{3}$ and $\mathrm{AgH}_{3}$ may be passive, it seems that substitutional $\mathrm{Pd}$ and $\mathrm{Pt}$ cannot be inactivated by $\mathrm{H}$. However, molecular hydrides of all the metal impurities are passive when inserted into microvoids. The calculations highlight several levels which remain to be detected, e.g. the (-/0) levels of $\mathrm{AuH}_{2}, \mathrm{AgH}_{2}$ and $\mathrm{PtH}$. The observation 
of shallow donor levels E(90) and E(60) in Pt and Pd doped material respectively suggests to us that $\mathrm{H}$ does not simply aggregate around substitutional TM impurities.

\section{References}

[1] To appear in Identification of Defects in Semiconductors, edited by M. Stavola and Semiconductors and Semimetals, treatise editors, R. K. Willardson, A. C. Beer and E. R. Weber (Academic Press).

[2] A. Resende, J. Goss, P. R. Briddon, S. Öberg and R. Jones, Mater. Sci. Forum, 258-63, 295 (1997).

[3] N. Yarykin, J.-U. Sachse, J. Weber and H. Lemke, Mater. Sci. Forum, 258-63, 301 (1997).

[4] E. Ö Sveinbjörnsson and O. Engström, Phys. Rev. B52, 4884 (1995).

[5] J.-U. Sachse, J. Weber and H. Lemke, Mater. Sci. Forum, 258-63, 307 (1997).

[6] J.-U. Sachse, E. Ö. Sveinbjörnsson, W. Jost, J. Weber and H. Lemke, Phys. Rev. B55, 16176 (1997).

[7] A. Resende, R. Jones, S. Öberg, and P. R. Briddon, this conference.

[8] J. A. Davidson and J. H. Evans, Semicond. Sci. Technol. 11, 1704 (1996).

[9] S. J. Uftring, M. Stavola, P. M. Williams and G. D. Watkins, Phys. Rev. B51, 9612 (1995).

[10] B. Mohadjeri, J. S. Williams, and J. Wong-Leung, Appl. Phys. Lett., 66, 1889 (1995). 